\title{
UCP3 Ablation Exacerbates High-Salt Induced Cardiac Hypertrophy and Cardiac Dysfunction
}

\author{
Hongmei Lang ${ }^{\mathrm{a}}$ Yang Xiang ${ }^{\mathrm{b}}$ Zhihua Ai ${ }^{\mathrm{a}}$ Zhiqing You ${ }^{\mathrm{a}}$ Xiaolan Jin ${ }^{\mathrm{a}}$ Yong Wan $^{\mathrm{a}}$ \\ Yongjian Yang ${ }^{c}$
}

aDepartment of Endocrinology, Chengdu Military General Hospital, Chengdu, 'Department of Neurology, Chengdu Military General Hospital, Chengdu, 'Department of Cardiovascular, Chengdu Military General Hospital, Chengdu, China

\section{Key Words}

High salt $•$ Cardiac hypertrophy $\cdot$ Uncoupling protein $3 \cdot$ Elevated blood pressure

\begin{abstract}
Background/Aims: Excessive salt intake and left ventricular hypertrophy (LVH) are both critical for the development of hypertension and heart failure. The uncoupling protein 3 (UCP3) plays a cardio-protective role in early heart failure development. However, the potential role for UCP3 in salt intake and LVH is unclear. Methods: UCP3 ${ }^{--}$and $\mathrm{C} 57 \mathrm{BL} / 6$ mice were placed on either a normal-salt (NS, $0.5 \%)$ or a high-salt (HS, 8\%) diet for 24 weeks.The cardiac function, endurance capacity, energy expenditure, and mitochondrial functional capacity were measured in each group. Results: Elevated blood pressure was only observed in HS-fed $\mathrm{UCP} 3^{-/-}$mice. High salt induced cardiac hypertrophy and dysfunction were observed in both C57BL/6 and UCP3 ${ }^{-1-}$ mice. However, the cardiac lesions were more profound in HS-fed UCP31- mice.Furthermore, HS-fed UCP3 ${ }^{-1-m i c e}$ experienced more severe mitochondrial respiratory dysfunction compared with HS-fed C57BL/6 mice, represented by the decreased volume of oxygen consumption and heat production at the whole-body level. Conclusion: UCP3 protein was involved in the incidence of high-salt induced hypertension and the progression of cardiac dysfunction in the early stages of heart failure. UCP3 ablation exacerbated high-salt-induced cardiac hypertrophy and cardiac dysfunction.

\section{Introduction}

Excessive salt intake exacerbates hypertension and further increases left ventricular hypertrophy $(\mathrm{LVH})$ in clinical essential and experimental hypertension [1]. LVH and its related dysfunction are important independent risk factors for the development of heart failure [2]. Previous studies demonstrated that salt reduction had a significant effect on reducing $\mathrm{LV}$ mass and the risk of heart attack in either hypertensive or normotensive patients

Yongjian Yang

KARGER
Department of Cardiovascular, Chengdu Military General Hospital,

Chengdu (China)

E-Mail65704951@qq.com 
[3-5]. However, the pathophysiological mechanisms linking salt and LV hypertrophy remain unclear.

Mitochondria are the main sources of ATP production and occupy $30-40 \%$ of the cell volume in adult mammalian cardiomyocytes [6]. Both clinical and experimental studies have suggested that the dysfunction of mitochondrial bioenergetics may contribute to the development of cardiac hypertrophy [7]. We have previously reported that the activation of transient receptor potential vanilloid subtype 1 (TRPV1), a non-selective cation channel type, could attenuate the cardiac hypertrophy caused by high salt intake through improving mitochondrial function $[8,9]$.

Uncoupling proteins (UCPs) belong to the family of mitochondrial transporter proteins that mainly involve in uncoupling the electron transport chain from ATP synthesis, hence its main role is to produce heat instead of producing ATP [10]. In mammals, more than five UCP family members have been identified, including UCPs1-5. A previous study suggested that UCP2 ablation exacerbated high-salt intake-induced vascular dysfunctionand plays an important role in preventing salt-sensitive hypertension [11]. UCP3 had been implicated in energy and fatty acid metabolism [12]. Importantly, UCP3 is expressed in cardiac muscle, although its role is relatively unexplored. Several recent studies have suggested that UCP3 plays a cardio-protective role against lipid-induced mitochondrial dysfunction or reactive oxygen species(ROS)-mediated oxidative stress [13-15]. However, the potential cardioprotective role of UCP3 under long-term high-salt challenge remains unclear. Therefore, we hypothesised that UCP3 ablation exacerbates high salt intake-induced cardiac hypertrophy and cardiac dysfunction through the impairment of mitochondrial respiratory function.

\section{Materials and Methods}

\section{Animals}

The animal experimental procedures were performed in accordance with protocols and approved by Institutional Animal Care and Use Committee of Chengdu Military General Hospital. The UCP3 knockout mice (UCP3 ${ }^{-}$) were kindly donated from Professor Chenyu Zhang (Nanjing University, Nanjing, China). UCP $3 \%$ mice were generated on a C57BL/6 background. C57BL/6 mice were purchased from the Laboratory Animal Research Centre of Chengdu Military General Hospital (Chengdu, China).

The C57BL/ 6 ( $n=24$, aged 6 to 8 weeks old) and UCP3 $\%(n=24$, aged 6 to 8 weeks old) mice were randomly divided into the following groups: normal-salt diet (NS, $0.5 \% \mathrm{NaCl}$ by weight) and high-salt diet (HS, $8 \% \mathrm{NaCl}$ by weight). The mice were housed at a controlled temperature $\left(22 \pm 1^{\circ} \mathrm{C}\right)$ in a 12 -h light/12-h dark cycle, with water available ad libitum. The mice were maintained for 24 weeks, and their body weight, food intake, drinking water volume, blood pressure and heart rate were measured.

\section{Blood pressure measurement}

The tail-cuff method was used for blood pressure measurement (BP-2010A, Softron Biotechnology Co., Ltd, China). The tail of each mouse was passed through a cuff and immobilised by adhesive tape in a V-shaped block. The analysis was photoelectrically evaluated, as blood flow in the tail produces oscillating waves that were digitally sampled and displayed in real time on a monitor. Tail-cuff BP was automatically measured three times, and the average value of systolic BP was used.

\section{Echocardiography}

The animals were anaesthetised with $0.5-1 \%$ isoflurane and fixed to a heating pad in a supine position. Echocardiography was performed by using the in vivo micro-imaging system Vevo-770 (Visual Sonics) with a real-time micro visualisation scan head of $17.5 \mathrm{MHz}$ [17]. The hearts were imaged in the two-dimensional parasternal short-axis view and analysed in M-mode at the level of papillary muscles. The following parameters were measured: percentage of left ventricular fractional shortening (LVFS), LV ejection fraction, LV internal dimensions at both diastole and systole (LVIDd and LVIDs respectively), and LV posterior wall dimensions at both diastole and systole (LVPWd and LVPWs, respectively). The E/A ratio was assessed. LV mass was calculated using a standard cube formula, which assumed a spherical LV geometry according to 


\section{Cellular Physiology Cell Physiol Biochem 2018;46:1683-1692 \begin{tabular}{l|l} 
and Biochemistry Published 10.1159/000489244 & $\begin{array}{l}\text { C } 2018 \text { The Author(s). Published by S. Karger AG, Basel } \\
\text { www.karger.com/cpb }\end{array}$
\end{tabular}}

Lang et al.: UCP3 Ablation Exacerbates Cardiac Hypertrophy

the following formula: LV mass $=1.04 \times\left[(\text { IVSd }+ \text { LVIDd }+ \text { LVPWd })^{3}-(\text { LVIDd })^{3}\right]$, where 1.04 is the specific gravity of the myocardium. The derived LV mass was normalised for body weight (LVW/BW).

\section{Heart weight and histology analysis}

The mice were anaesthetised with $0.2 \mathrm{ml}$ i.p. injection of $10 \mathrm{mg}^{\mathrm{ml}} \mathrm{l}^{-1}$ sodium pentobarbitone. The hearts were quickly excised for either histology analysis or mitochondrial isolation. The hearts were weighed and washed in ice-cold PBS solution and then fixed in 4\% formaldehyde solution for $1 \mathrm{~h}$. Sections of $5 \mu \mathrm{M}$ in thickness were cut and stained with Haematoxylin and Eosin to analyse the tissue morphology.

\section{Endurance capacity}

A test for endurance with increasing workload was used to assess the mouse endurance capacity. Prior to this experiment, all mice were trained to run on the treadmill with $10 \mathrm{~m} / \mathrm{min}$ speed and $0^{\circ}$ inclination for $15 \mathrm{~min}$ each day. The test was initiated after acclimatisation to the treadmill, and the treadmill was set to a $10^{\circ}$ incline, which has been shown to elicit maximum $\mathrm{O}_{2}$ consumption in 8-month-old mice. The mice were forced to run at $10 \mathrm{~m} / \mathrm{min}$ for $10 \mathrm{~min}, 14 \mathrm{~m} / \mathrm{min}$ for $5 \mathrm{~min}$, and $18 \mathrm{~m} / \mathrm{min}$ until exhaustion, and exhaustion was defined as the failure to maintain workload and remain on the electrical grid for $4 \mathrm{~s}[18,19]$. Running Distance $=$ Belt Speed $(\mathrm{m} / \mathrm{min}) \times$ Time $(\mathrm{min})$. The running distance was recorded when the mice reached exhaustion.

\section{Energy expenditure}

Mice fed with HS or NS diet for 24 weeks were acclimatised to the monitoring cages for $24 \mathrm{~h}$ prior to data collection. The mice were weighed prior to housing in monitoring cages. Carbon dioxide $\left(\mathrm{CO}_{2}\right)$ and oxygen $\left(\mathrm{O}_{2}\right)$ content were calibrated. All data were automatically collected by the Comprehensive Laboratory Animal Monitoring System (CLAMS, Columbus Instruments, OH, USA) in subsequent experiments.

\section{Isolation of mitochondria}

The left ventricle of the heart was cut into fragments and homogenised in a glass homogeniser. Cardiac mitochondria were isolated by differential centrifugation using a commercial kit (Beyotime Institute of Biotechnology, Shanghai, China). The mitochondria were suspended in MiR05. The final mitochondrial suspension was immediately used to measure mitochondrial respiratory parameters, and the samples were stored at $-80^{\circ} \mathrm{C}$. The concentration of the mitochondrial suspension was measured using a protein assay kit (Beyotime Institute of Biotechnology, Shanghai, China).

\section{Measurement of mitochondrial respiratory parameters}

The respiratory rates of the cardiac mitochondria of the were monitored at $37^{\circ} \mathrm{C}$ using the $0 x y g r a p h-2 \mathrm{k}$ (Oroboros, Innsbruck, Austria) with two 2-ml chambers. The respiratory rates were analysed by the DatLab software package. The protein from approximately $1 \mathrm{mg}$ of mitochondria was added to each chamber after respiration stabilisation. The leak respiration of complex I (CI LEAK) was measured by the addition of Glutamate $(5 \mathrm{mM})$ and malate $(2 \mathrm{mM})$ as substrates. The oxidative phosphorylation of CI (CI OXPHOS) was determined after the addition of ADP $(5 \mathrm{mM})$. Cytochrome $\mathrm{c}(10 \mu \mathrm{M})$ was added to evaluate the integrity of the outer mitochondrial membrane. The oxidative phosphorylation capacity of CI+II (CI+II OXPHOS, state P) was stimulated by the addition of succinate $(2.5 \mathrm{mM})$. Further addition of oligomycin $\left(1 \mu \mathrm{g} \cdot \mathrm{ml}^{-1}\right)$ after $\mathrm{CI}+\mathrm{II}$ OXPHOS determination facilitated the measurement of leak respiration (state $\mathrm{L}$ ). The capacity of the electron transport chain (ETS, state E) was titrated after the addition of uncoupler FCCP (injected stepwise up to 1-1.5 $\mu \mathrm{M})$. The respiration of CII was evaluated after the addition of rotenone $(0.5 \mu \mathrm{M})$, an inhibitor of $\mathrm{CI}$, through inhibiting Complex I respiration. Residual oxygen consumption (ROX) was evaluated after the inhibition of CIII with antimycin A $(2.5 \mu \mathrm{M})$.

\section{Detection of the ATP level}

The level of cardiac mitochondrial adenosine 5'-triphosphate (ATP) was measured using a firefly luciferase-based ATP assay kit (Beyotime Institute of Biotechnology, Shanghai, China) according to the manufacturer's instructions. The level of ATP was normalised to the mitochondrial protein concentration.

Western blotting analysis

The UCP3 expression was assessed by western blotting analysis, and the samples were normalised to VDAC protein. Mitochondrial protein extraction was blocked with PBS-5\% fat-free dried milk at room 


\section{Cellular Physiology Cell Physiol Biochem 2018;46:1683-1692

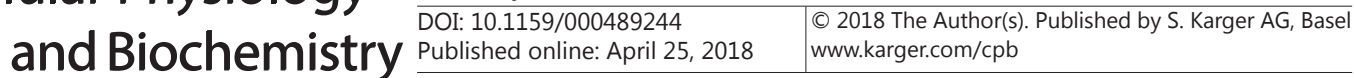 \\ Lang et al.: UCP3 Ablation Exacerbates Cardiac Hypertrophy}

temperature for $1 \mathrm{~h}$, and incubated overnight at $4-8^{\circ} \mathrm{C}$ with anti-UCP3 (1:1000, ab-3477,Abcam), and antiVDAC (1:1000, ab-61273, Abcam) antibodies.

Mouse tail gene identification [20]

At fifteen days after birth, the tails of the mice were collectedand digested overnight at $55^{\circ} \mathrm{C}$ by tissue cracking buffer containing protease K. DNA was extracted from the mice tailsas previously described. PCR were employed to genotype mice identification. The following primer sequences were used for detection: 5'CCT CCA CTC ATG ATC TAT AGA TC3', 5'GCA CTG CGG CCT GTT TTG3', and 5'ACC CTC TGT GCG CAC CAT AGT CA3'. The PCR products were analysed by agarose electrophoresis.

\section{Statistical analysis}

The results aredescribed as the means \pm SD. The data were evaluated with SPSS 12.0 software (SPSS Inc., Chicago, IL). Comparisons between groups were analysed by Student's t-test or ANOVA with the StudentNewman-Keuls post hoc correction. A value of $\mathrm{P}<0.05$ was considered statistically significant.

\section{Results}

UCP3 deficiency aggravated HS-induced cardiac hypertrophy and cardiac dysfunction

The HS-fed UCP ${ }^{-}$mice showed elevated systolic BP values compared to those of NSfed UCP $\%$ mice $(112 \pm 7 \mathrm{mmHg}$ vs. $104 \pm 7 \mathrm{mmHg}$, respectively, $P<0.05)$, which was absent in C57BL/6 mice (Table 1). The genotype of UCP3 $\%$ mice was identified by Southern blot analysis and multiplex PCR.A 600-bp band was detected in wild typemice, and an insertion mutation band of $300 \mathrm{bp}$ was detected in UCP3 KO mice (Fig. 1A).We examined the impact of long-term HS diet on morphologic changes in the heart. The enlargement of the cardiac wall and an increase in the heart weight to body weight ratio (HW/BW) was observed in HS-fed C57BL/6 and UCP3 $\%$ micecompared to their NS-fed counterparts (Fig. 1B-E). The $\mathrm{HW} / \mathrm{BW}$ ratiowas also increased in HS-fed UCP3 $\%$ mice compared to that in HS-fed C57BL/6 mice (Fig. 1C). A parasternal short-axis echocardiogram of C57BL/6 and UCP3 ${ }^{-1}$ mice was obtained at the level of the papillary muscles (Fig. 1D and 1E). The thickness of the diastolic left ventricular posterior wall $\left(\mathrm{LVPW}_{\mathrm{d}}\right)$ and the anterior/interventricular septal wall $\left(\mathrm{IVS}_{\mathrm{d}}\right)$ were significantly increased in HS-fed mice compared with those in NS-fed mice. Compared with those in NS-fed mice, the thickness of LV internal diameter during diastole (LVID ${ }_{d}$ ) in HS-fed mice was significantly decreased (Table 2). No differences were found in the \% ejection fraction and \% fractional shortening between WT and UCP $3^{\%}$ mice (Table 2).

To assess changes in cardiac function under HS diet and explore the potential role of UCP3, the transmitralDoppler indices (peak velocities of the early [E] and late $[A]$ waves and the E/A ratio) were measured(Fig.1E). A significant reduction in the heart $\mathrm{E} / \mathrm{A}$ ratio suggested cardiac diastolic dysfunction in HS-fed mice. Compared with C57BL/6 mice, the heart E/A ratio in UCP3 ${ }^{-/}$mice was markedly declined (Table 2). Compared with normal-salt diet, the expression of UCP3 in animals fed a high-salt diet was significantly decreased in C57BL/6 mice(Fig.1F and $1 \mathrm{G})$.These findings demonstrated that the knockout of UCP3 plays a detrimental role in HS-induced cardiac disturbance.

UCP3 ablation exacerbated the HSmediated decrement of cardiac reserve function and energy expenditure

Cardiac reserve function was determined by endurance test, which

Table 1. General characteristics of C57BL/6 and UCP $\%$ mice treated with a normal-salt diet or high-salt diet. Values are expressed as the means $\pm \mathrm{SD} ;{ }^{*} \mathrm{P}<0.05,{ }^{* *} \mathrm{P}<0.01$ compared with different diet; ${ }^{~} \mathrm{P}<0.05$ compared with $\mathrm{C} 57 \mathrm{BL} / 6$ mice on a high-salt diet

\begin{tabular}{lccccc}
\hline & \multicolumn{2}{c}{ C57BL/6 } & \multicolumn{2}{c}{ UCP3 $\%$} \\
\hline Weight (g) & 10 & $27.7 \pm 1.6$ & $26.8 \pm 2.6$ & $27.4 \pm 2.2$ & $26.9 \pm 2.0$ \\
SBP (mmHg) & 10 & $106 \pm 8$ & $108 \pm 8$ & $104 \pm 7$ & $112 \pm 7^{\#}$ \\
& & & & & \\
HR (beat/min) & 10 & $491 \pm 54$ & $494 \pm 51$ & $498 \pm 42$ & $501 \pm 59$ \\
& & & & & \\
Food intake (g/day) & 10 & $3.7 \pm 0.6$ & $3.5 \pm 0.5$ & $3.8 \pm 0.6$ & $3.5 \pm 0.4$ \\
Water (ml/day) & 10 & $4.5 \pm 0.5$ & $6.1 \pm 1.1^{* *}$ & $4.5 \pm 1.1$ & $5.7 \pm 0.6^{*}$ \\
\hline
\end{tabular}




\section{Cellular Physiology Cell Physiol Biochem 2018:46:1683-1692

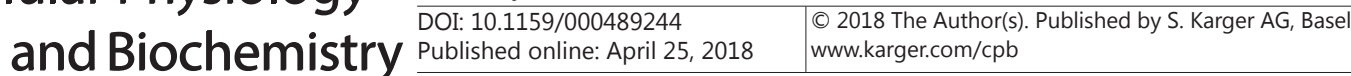 Lang et al.: UCP3 Ablation Exacerbates Cardiac Hypertrophy}

Fig. 1. Effects of UCP3 knockout on high salt-induced cardiac morphology and cardiac dysfunction. (A) Genotyping of UCP3 knockout mice and wild-type littermates. (B) Representative images of cardiac morphology with H\&E staining of coronal section. Scale bar denotes $2000 \mu \mathrm{m}$. Each $\mathrm{n}=10$. (C) The heart weight (HW) and heart weight/body weight (HW/BW) ratio. (D) Representative images of M-mode echocardiography. (E) Representative E and $\mathrm{A}$ waves of mitral valve. Each $\mathrm{n}=10$. Data are presented as the means \pm SD. Each $n=10 .{ }^{*} p<0.05$ vs NS. (F) Representative blots of UCP3. (G) Quantitative analysis of UCP3 expression in C57BL/ 6 and UCP3-/mice fed HS and NS diets. The values are presented as the means $\pm \operatorname{SEM}(n=6) .{ }^{*} \mathrm{P}<0.05$.

involved an incremental protocol with increasing workloads. During the test, the mice were forced to run on the treadmill until exhaustion. In both UCP3 $\%$ and C57BL/6 mice, HS diet was associated with apparently impaired cardiac reserve function, represented by the shorter running distance (Fig.2A). Importantly, the total running distance was even shorter in HS-fed UCP $3^{--}$mice compared with $\mathrm{C} 57 \mathrm{BL} / 6$ mice ( $302 \pm 49$ m vs. $367 \pm 52 \mathrm{~m}, P<0.05$ ). Thus, this finding indicated that UCP3 deficiency could aggregate HS-induced decrement of cardiac reserve function.

The endurance performance is directly related to the energy expenditure, and we next examined the effects of UCP3 knockout onHS-diet induced energy expenditure changes at a whole-body level. The total oxygen consumption and heat production of C57BL/ 6 and UCP3 $\%$ mice were assessed using CLAMS. HS-fed mice showed decreased oxygen consumption $\left(\mathrm{V}_{02}\right)$ and heat production compared with their NSfed counterparts (Table 3). No significant differences were found in $\mathrm{V}_{02}$ and heat production between C57BL/6 and UCP3 1- mice fed NS diets (Table 3). In contrast, HS-fed UCP $3^{\%}$ mice showed an apparent decrease in both $\mathrm{V}_{02}\left(2443 \pm 86 \mathrm{ml} \cdot \mathrm{kg}^{-1} \cdot \mathrm{hr}^{-1}\right.$ vs. $\left.3100 \pm 113 \mathrm{ml} . \mathrm{kg}^{-1} \cdot \mathrm{hr}^{-1}, P<0.01\right)$ and heat production $\left(0.34 \pm 0.011 \mathrm{kcal}^{-1} \cdot \mathrm{h}^{-1}\right.$ vs. $0.39 \pm 0.005$ $\mathrm{kcal}^{-1} \cdot \mathrm{h}^{-1}, P<0.01$ ) compared with HS-fed WT mice (Table 3, Fig. 2B-2C). Thereby, UCP3 deficiency could exacerbatethe decrement in HS-inducedenergy expenditure.

UCP3 deficiency aggravated mitochondrial dysfunction and reduction of ATP production in HS-fed mice

Mitochondrial function and its related ATP production are pivotal for the maintenance of cardiac function.We measured the ATP level of cardiac mitochondria in C57BL/6 and

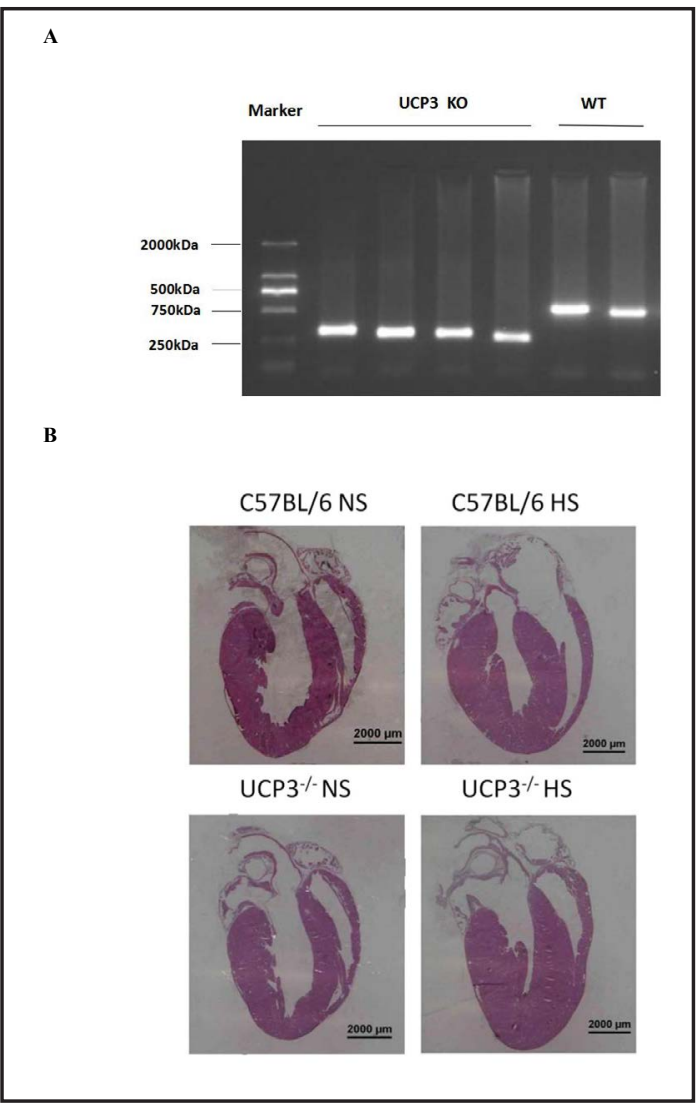

Table 2. Echocardiographic characteristics C57BL/6 and UCP $3 \%$ mice treated with a normal-salt diet or high-salt diet. Values are expressed as the means \pm $\mathrm{SD} ;{ }^{*} \mathrm{P}<0.05,{ }^{* *} \mathrm{P}<0.01$ compared with different diet; ${ }^{\#} \mathrm{P}<0.05$ compared with $\mathrm{C} 57 \mathrm{BL} / 6$ mice on a high-salt diet

\begin{tabular}{lccccc}
\hline & \multicolumn{2}{c}{ C57BL/6 } & \multicolumn{2}{c}{ UCP3 $\%$} \\
& $\mathrm{n}$ & NS & HS & NS & HS \\
\hline IVS.d (mm) & 10 & $0.94 \pm 0.08$ & $1.24 \pm 0.11^{* *}$ & $1.03 \pm 0.10$ & $1.38 \pm 0.09^{* *}$ \\
LVID.d (mm) & 10 & $3.87 \pm 0.22$ & $3.16 \pm 0.17^{* *}$ & $3.52 \pm 0.16$ & $3.13 \pm 0.22^{* *}$ \\
LVPW.d (mm) & 10 & $0.90 \pm 0.11$ & $1.08 \pm 0.08^{* *}$ & $0.95 \pm 0.19$ & $1.21 \pm 0.10^{* *}$ \\
EF\% & 10 & $83.02 \pm 4.41$ & $79.8 \pm 7.85$ & $81.74 \pm 3.83$ & $79.86 \pm 2.03$ \\
FS\% & 10 & $60.75 \pm 4.89$ & $58.92 \pm 5.75$ & $62.24 \pm 6.45$ & $60.55 \pm 1.86$ \\
E/A ratio & 10 & $1.92 \pm 0.19$ & $1.55 \pm 0.29^{*}$ & $1.81 \pm 0.34$ & $1.25 \pm 0.14^{* *}$ \\
Heart Rate (beat/min) & 10 & $430 \pm 21$ & $418 \pm 17$ & $438 \pm 23$ & $428 \pm 21$ \\
LV mass (mg) & 10 & $96.93 \pm 10.53$ & $118.14 \pm 14.55^{*}$ & $102.34 \pm 11.44$ & $125.66 \pm 15.58^{* *}$
\end{tabular}


$\mathrm{UCP}^{\%}$ mice fed HS and NS diets for 24 weeks. No significant difference in the ATP level was observed between in C57BL/6 and $\mathrm{UCP} 3 \%$ mice on a NS diet, 42.7 \pm 2.3 (nmol. $\mathrm{mg}^{-1}$ protein) versus $42.2 \pm 2.7$ (nmol.mg-1 protein), respectively. Similar results were obtained, showing that the production of ATP was diminished in C57BL/6 and UCP $3^{-/}$mice on a HS diet, and ATP level decreased by $8.3 \%$ and $14.7 \%$, respectively (Table 4). We next analysed the mitochondrial respiration capacity in cardiac mitochondria isolated from C57BL/6 and UCP $3 \%$ mice fed either a NS or HS diet. Among the mice in the NS-fed group, there were no overt differences in mitochondrial respiratory capacity, except the CI+II OXPHOS between C57BL/6 and $\mathrm{UCP}^{\%}$ mice (Fig. 3A). In contrast, HS-fed $\mathrm{UCP}^{\%}$ mice showed a remarkably decreased capacity of CIOXPHOS, CI+II OXPHOS, CI+II ETS, and CII ETS, which decreased by $36.4 \%, 26.1 \%, 17 \%$, and $32.8 \%$, respectively (Fig. $3 \mathrm{~B}$ ). The $\mathrm{P} / \mathrm{L}$ ratio is an index of coupling control at a specific substrate supply and displays the capacity of OXPHOS over leak respiratory, and the $\mathrm{L} / \mathrm{E}$ ratio reveals the maximum capacity of the ETS needed to compensate for proton leak. HS-fed UCP3 ${ }^{\%}$ mice were associated with decreased P/L ratio ( $2.28 \pm 1.13$ vs. $2.66 \pm 0.87)$ and increased $L / E$ ratio $(0.49 \pm 0.23$ vs. $0.42 \pm 0.19$ ). Altogether, these data suggest that UCP3 plays a potential protective role in the mitochondrial respiratory dysfunction mediated by high salt intake.

\section{Discussion}

The present study demonstrates several novel findings regarding the important role of UCP3 in high-salt mediated cardiac hypertrophy and dysfunction.First, we showed that long-term high-salt caused cardiac hypertrophy, and cardiac dysfunction was more severe in UCP $3 \%$ mice than in C57BL/6 mice. Compared with C57BL/6 mice, HS-fed UCP3\%-mice had significantly decreased cardiac reserve function and volume oxygen and heat production at the whole-body level. Furthermore, the UCP3 deficiency exacerbated mitochondrial 
respiratory dysfunction mediated by high salt intake. These results suggested that UCP3 might be a potential molecular target in the pathophysiological mechanism linking salt-sensitive hypertension and cardiac hypertrophy.

Salt sensitivityrefers to the dependence of BP on salt intake, which can be detected in half of patients with hypertension and one-fourth of normotensive subjects [21]. Several epidemiological studies have shown that salt sensitivity is influenced by race, age and gender, and South American and elderly individuals are more likely to experience salt-sensitive hypertension [22, 23]. Experimental studies have indicated that salt sensitivity is correlatedwith the strain of rat or mouse [24]. The results of the present study suggested that UCP $3 \%$ mice were more susceptible to elevated blood pressure than C57BL/ 6 mice under high salt intake, supporting a potential role for UCP3 in salt sensitivity.

Salt-induced LV hypertrophy primarily occurs in the interventricular septum [25]. The present findings also support the above idea. Increasing evidence has suggested that highsalt is directly linked to left ventricular hypertrophy, independent of blood pressure. The present study showed that salt overload induced LV hypertrophy in control animals, independent of increased blood pressure. Therefore, we speculated that high salt intake might be an independent risk factor for cardiac hypertrophy. Currently, the mechanism responsible for highsaltinduced cardiac hypertrophy remains unclear. Severalmechanisms, such as the overstimulation of the sympathetic activity and activation of the renin-angiotensin system, have been implicated in the development of cardiac hypertrophy mediated by high salt intake [25]. Antagonising sympathetic activity or activation of the renin-angiotensin system can effectively improve cardiac hypertrophy and dysfunction in both human and animal heart failure $[26,27]$. The present results implicated UCP3 protein in the pathophysiology mechanism for a link between salt-sensitive hypertension and cardiac hypertrophy.

We observed that high salt intake reduced the expression of UCP3 in cardiac mitochondria. Although the difference in LV hypertrophy between UCP3 $\%$ and C57BL/6 mice is small, this effect was significantly increased in HS-fed UCP $3 \%$ mice compared with that in HS-fed C57BL/6 mice. The physiological role of cardiac UCP3 remains unknown, and theavailable datado not provide a unified answer. Previous studies have suggested that energy deficiency in cardiac muscle is related to heart failure, and UCP3 might contribute to thisenergy deficiency. We examined the energy expenditure of $\mathrm{C} 57 \mathrm{BL} / 6$ and UCP3 $\%$ mice under long-term high salt intake. The results suggested that UCP3 ablation exposure to high salt intake impacted the energy metabolism through 
decreasing oxygen volume and heat production at the whole-body level. The role of UCP3 in the development of cardiac remodelling might be associated with mitochondrial respiration, except for elevated BP.

Subsequently, cardiac mitochondrial respiratory measurement further supported this hypothesis, andan overall reduction in mitochondrial respiratory was found in UCP3 $\%$ mice under conditions of high salt. Therefore, cardiac UCP3 could also protect the heart against salt-sensitive hypertension-induced cardiac hypertrophy. UCP3 showed a beneficial effect in the development of cardiac remodelling mediated by salt-sensitive hypertension. The absence of UCP3 under conditions of high salt exposure reduced ATP production, resulting in abnormalities in the energy metabolism of cardiac muscle. Clinical and experimental studies suggested that UCP3 played a cardio-protective role in the development of early heart failure $[28,29]$. Energy deficiency in heart failure might result from increased mitochondrial UCPs (i.e., less efficient ATP synthesis) and depleted GLUT4 (i.e., reduced glucose uptake) [30]. The increased UCP3 level is likely to contribute to an adaptive response in the failing heart. UCP3 likely delayed the progression of the early stages of heart failure through the reduction of reactive oxygen species production [15].

\section{Conclusion}

High salt intake is an independent risk factor for cardiac hypertrophy. The results of the present study suggest that UCP3 protein is involved in the incidence of salt-sensitive hypertension and the progression of cardiac dysfunction in the early stages of heart failure. Mitochondrial respiratory dysfunction contributes to the cardiac hypertrophy induced by salt-sensitive hypertension. Regardless of the precise operating mechanism, UCP3 protects mitochondria against cardiac remodelling mediated by salt-sensitive hypertension, making thisprotein a potential player in the development of early heart failure caused by saltsensitive hypertension. However, the deficiency of this study was that the difference of results was slight and the data were not be repeatedly measured, which might lead to not reproducibility of the obtained results. Therefore, more researches are needed to further confirm the role of UCP3 in the heart.

\section{Acknowledgements}

Thepresent study was funded by the Youth Innovation Talent Fund (41732C11C).

\section{Disclosure Statement}

The authors have no conflicts to disclose.

\section{References}

1 Koga Y, Hirooka Y, Araki S, Nozoe M, Kishi T, Sunagawa K: High salt intake enhances blood pressure increase during development of hypertension via oxidative stress in rostral ventrolateral medulla of spontaneously hypertensive rats. Hypertens Res 2008;31:2075-2083.

-2 Katz AM: Cardiomyopathy of overload. A major determinant of prognosis in congestive heart failure. $\mathrm{N}$ Engl J Med 1990;322:100-110.

-3 MacGregor GA, Markandu ND, Sagnella GA, Singer DR, Cappuccio FP: Double-blind study of three sodium intakes and long-term effects of sodium restriction in essential hypertension. Lancet 1989;2:1244-1247. 


\section{Cellular Physiology Cell Physiol Biochem 2018;46:1683-1692

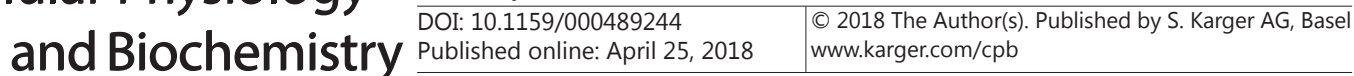

4 Sacks FM, Obarzanek E, Windhauser MM, Svetkey LP, Vollmer WM, McCullough M, Karanja N, Lin PH, Steele P, Proschan MA, et al.: Rationale and design of the Dietary Approaches to Stop Hypertension trial (DASH). A multicenter controlled-feeding study of dietary patterns to lower blood pressure. Ann Epidemiol 1995;5:108-118.

-5 Sacks FM, Svetkey LP, Vollmer WM, Appel LJ, Bray GA, Harsha D, Obarzanek E, Conlin PR, Miller ER, 3rd, Simons-Morton DG, Karanja N, Lin PH: Effects on blood pressure of reduced dietary sodium and the Dietary Approaches to Stop Hypertension (DASH) diet. DASH-Sodium Collaborative Research Group. N Engl J Med 2001;344:3-10.

-6 Huang X, Sun L, Ji S, Zhao T, Zhang W, Xu J, Zhang J, Wang Y, Wang X, Franzini-Armstrong C, Zheng M, Cheng $\mathrm{H}$ : Kissing and nanotunneling mediate intermitochondrial communication in the heart. Proc Natl Acad Sci U S A 2013;110:2846-2851.

7 Rosca MG, Hoppel CL: Mitochondria in heart failure. Cardiovasc Res 2010;88:40-50.

8 Lang H, Li Q, Yu H, Li P, Lu Z, Xiong S, Yang T, Zhao Y, Huang X, Gao P, Zhang H, Shang Q, Liu D, Zhu Z: Activation of TRPV1 attenuates high salt-induced cardiac hypertrophy through improvement of mitochondrial function. Br J Pharmacol 2015;172:5548-5558.

-9 Yang D, Luo Z, Ma S, Wong WT, Ma L, Zhong J, He H, Zhao Z, Cao T, Yan Z, Liu D, Arendshorst WJ, Huang Y, Tepel M, Zhu Z: Activation of TRPV1 by dietary capsaicin improves endothelium-dependent vasorelaxation and prevents hypertension. Cell Metab 2010;12:130-141.

10 Jia JJ, Zhang X, Ge CR, Jois M: The polymorphisms of UCP2 and UCP3 genes associated with fat metabolism, obesity and diabetes. Obes Rev 2009;10:519-526.

11 Ma S, Ma L, Yang D, Luo Z, Hao X, Liu D, Zhu Z: Uncoupling protein 2 ablation exacerbates high-salt intakeinduced vascular dysfunction. Am J Hypertens 2010;23:822-828.

12 Bezaire V, Seifert EL, Harper ME: Uncoupling protein-3: clues in an ongoing mitochondrial mystery. FASEB J 2007;21:312-324.

13 Perrino C, Schiattarella GG, Sannino A, Pironti G, Petretta MP, Cannavo A, Gargiulo G, Ilardi F, Magliulo F, Franzone A, Carotenuto G, Serino F, Altobelli GG, Cimini V, Cuocolo A, Lombardi A, Goglia F, Indolfi C, Trimarco B, Esposito G: Genetic deletion of uncoupling protein 3 exaggerates apoptotic cell death in the ischemic heart leading to heart failure. J Am Heart Assoc 2013;2:e000086.

14 Boehm EA, Jones BE, Radda GK, Veech RL, Clarke K: Increased uncoupling proteins and decreased efficiency in palmitate-perfused hyperthyroid rat heart. Am J Physiol Heart Circ Physiol 2001;280:H977-983.

15 Murray AJ, Cole MA, Lygate CA, Carr CA, Stuckey DJ, Little SE, Neubauer S, Clarke K: Increased mitochondrial uncoupling proteins, respiratory uncoupling and decreased efficiency in the chronically infarcted rat heart. J Mol Cell Cardiol 2008;44:694-700.

-16 Kurtz TW, Griffin KA, Bidani AK, Davisson RL, Hall JE: Recommendations for blood pressure measurement in humans and experimental animals. Part 2: Blood pressure measurement in experimental animals: a statement for professionals from the subcommittee of professional and public education of the American Heart Association council on high blood pressure research. Hypertension 2005;45:299-310.

-17 Rueda-Clausen CF, Morton JS, Davidge ST: Effects of hypoxia-induced intrauterine growth restriction on cardiopulmonary structure and function during adulthood. Cardiovasc Res 2009;81:713-722.

-18 Faldt J, Wernstedt I, Fitzgerald SM, Wallenius K, Bergstrom G, Jansson JO: Reduced exercise endurance in interleukin-6-deficient mice. Endocrinology 2004;145:2680-2686.

19 Meek TH, Lonquich BP, Hannon RM, Garland T, Jr.: Endurance capacity of mice selectively bred for high voluntary wheel running. J Exp Biol 2009;212:2908-2917.

-20 Zhang CY, Baffy G, Perret P, Krauss S, Peroni O, Grujic D, Hagen T, Vidal-Puig AJ, Boss O, Kim YB, Zheng XX, Wheeler MB, Shulman GI, Chan CB, Lowell BB: Uncoupling protein-2 negatively regulates insulin secretion and is a major link between obesity, beta cell dysfunction, and type 2 diabetes. Cell 2001;105:745-755.

-21 Weinberger MH: Salt sensitivity as a predictor of hypertension. Am J Hypertens 1991;4:615S-616S.

22 Luft FC, Miller JZ, Grim CE, Fineberg NS, Christian JC, Daugherty SA, Weinberger MH: Salt sensitivity and resistance of blood pressure. Age and race as factors in physiological responses. Hypertension 1991;17:I102-108.

23 Oparil S, Miller AP: Gender and blood pressure. J Clin Hypertens (Greenwich) 2005;7:300-309.

-24 Rapp JP, Dene H: Development and characteristics of inbred strains of Dahl salt-sensitive and salt-resistant rats. Hypertension 1985;7:340-349. 


\section{Cellular Physiology Cell Physiol Biochem 2018;46:1683-1692

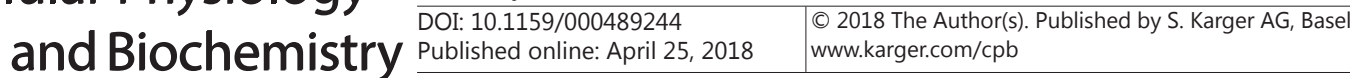 \\ Lang et al.: UCP3 Ablation Exacerbates Cardiac Hypertrophy}

25 Le Corvoisier P, Adamy C, Sambin L, Crozatier B, Berdeaux A, Michel JB, Hittinger L, Su J: The cardiac reninangiotensin system is responsible for high-salt diet-induced left ventricular hypertrophy in mice. Eur J Heart Fail 2010;12:1171-1178.

26 Lal A, Veinot JP, Leenen FH: Prevention of high salt diet-induced cardiac hypertrophy and fibrosis by spironolactone. Am J Hypertens 2003;16:319-323.

-27 Machackova J, Sanganalmath SK, Barta J, Dhalla KS, Dhalla NS: Amelioration of cardiac remodeling in congestive heart failure by beta-adrenoceptor blockade is associated with depression in sympathetic activity. Cardiovasc Toxicol 2010;10:9-16.

28 McFalls EO, Sluiter W, Schoonderwoerd K, Manintveld OC, Lamers JM, Bezstarosti K, van Beusekom HM, Sikora J, Ward HB, Merkus D, Duncker DJ: Mitochondrial adaptations within chronically ischemic swine myocardium. J Mol Cell Cardiol 2006;41:980-988.

29 Ozcan C, Palmeri M, Horvath TL, Russell KS, Russell RR, 3rd: Role of uncoupling protein 3 in ischemiareperfusion injury, arrhythmias, and preconditioning. Am J Physiol Heart Circ Physiol 2013;304:H11921200.

30 Murray AJ, Anderson RE, Watson GC, Radda GK, Clarke K: Uncoupling proteins in human heart. Lancet 2004;364:1786-1788. 